\title{
On Improving Text Readability by Creating a Personal Writing Style
}

\author{
Yuru Shen ${ }^{1}$ \\ ${ }^{1}$ School of Foreign Languages, Leshan Normal University, Sichuan, China \\ Correspondence: Yuru Shen, School of Foreign Languages, Leshan Normal University, No. 778, Binhe Road, \\ Leshan, Sichuan, 614004, China. Tel. 86-136-9615-4790. E-mail: sheng8632@163.com
}

Received: January 8, 2016 Accepted: February 7, 2017 Online Published: February 8, 2017

doi: 10.5539/elt.v10n3p95 URL: http://doi.org/10.5539/elt.v10n3p95

\begin{abstract}
English writing is one of the four indispensable skills that English learners need to master, but unfortunately, many Chinese college students have much difficulty composing clear, concise and coherent essays although they have studied English for at least over six years. To address the problem, the researchers and teachers in China have tried various methods, which have undoubtedly more or less played a role in helping students improve their writing, but with no obvious result. Besides, although much research has been done on readability formulas, the main factors that influence text readability, and so on, little research has been done on how to improve text readability, or how to produce readable writing. This paper, based on a brief introduction to readability and a brief account of the studies on readability and an analysis of the factors that affect text readability, proposes that we can improve the readability of a text by creating our own writing style.
\end{abstract}

Keywords: improve, text readability, create, personal writing style

\section{Introduction}

John Galsworthy (1867-1933), an English novelist and playwright, once said, "As a man lives and thinks, so will he write," which well illustrates the importance of writing. English writing is one of the four indispensable skills that English learners need to master, but unfortunately, many Chinese college students have much difficulty composing clear, concise and coherent essays although they have studied English for at least over six years. They may know clearly why to write and what to write about, but for various reasons they always make mistakes of this or that kind, of which the following are the most commonly seen in their writing: syntax errors, like sentence fragments, false parallelism, misplaced modifiers, dangling modifiers, run-together sentences and comma splices; grammatical mistakes, such as subject-verb disagreement and improper or wrong use of tenses and voices; inappropriate or unidiomatic or repetitive or even wrong use of words and phrases; word-for-word translation from Chinese to English; lack of cohesion and coherence either between sentences or between paragraphs; lack of a strong thesis; lack of evidence or details; and so on.

To address the problems, the researchers and teachers in China have tried various methods, such as offering them excellent essays written by native English speakers in the hope that they can learn from the sample essays how to write an essay with a strong thesis supported with adequate evidence and details, how to construct effective sentences and how to use words and phrases exactly, idiomatically and appropriately, and assigning them large numbers of after-class reading tasks in the hope of expanding their vocabulary because it is believed that the larger vocabulary a person has, the better essays he or she can write. The approaches employed have undoubtedly more or less played a role in helping students improve their writing, but with no obvious result. Besides, although much research has been done on readability formulas, the main factors that influence text readability, and so on, little research has been done on how to improve text readability, or how to produce readable writing. This paper, based on a brief introduction to readability and a brief account of the studies on readability and an analysis of the factors that affect text readability, proposes that we can improve the readability of a text by creating our own writing style.

\section{Definition of Readability}

The term "readability" is of recent origin, but "the attempt to improve texts, to derive rules for communicating more effectively and for assessing success at communication is a goal that reaches back at least as far as Aristotle's Rhetoric (Aristotle, 1991), in which various strategies for making texts effective vehicles for communicating arguments are discussed and assessed. The tradition continued through the medieval period 
(Murphy, 1971) and into the modern era in the numerous rhetorical and compositional handbooks" (Bailin \& Grafstein, 2001, p. 285).

Different scholars have paid attention to different aspects of readability and therefore defined it differently. For instance, Dreyer (1984) defines readability as "a text's legibility, power to interest, ease of understanding or any combination of these factors" (p. 334), which sums up the main features of readability; Gretchen Hargis and her colleagues at IBM (1998) think of readability as "the ease of reading words and sentences" (qtd. in DuBay, 2004), which stresses the attribute of clarity; G. Harry McLaughlin (1969) regards readability as "the degree to which a given class of people find certain reading matter compelling and comprehensible" (qtd. in DuBay, 2004), which emphasizes the interaction between the text and the reader. Although different in wording and focus, the definitions mentioned above have something in common: "readability" means how easily a reader can process the written language or how clearly a text expresses the writer's ideas and emotions.

\section{Studies about Readability}

Text readability has long been studied from different perspectives and with different emphases. For instance, George R. Klare's article “Assessing Readability" (1974-1975) reviews formulas and related predictive devices since 1960; Martin Nystrand's essay "Using Readability Research to Investigate Writing" (1979) calls the reader's attention to some promising studies of readability, particularly those employing the cloze technique; Fry's paper "Readability Versus Leveling" (2002) discusses some similarities and differences between readability formulas and leveling procedures and reports some current large-scale uses of readability formulas; William H. DuBay's article "The Principles of Readability" (2004) gives an account of the short history of literacy studies in the U.S. and that of research in readability and the readability formulas; the paper "What Is Readability"(Anonymous, 2008) analyzes the main factors that influence text readability, such as physical factors, reader factors, text structure, text coherence and cohesion, vocabulary difficulty, and syntax, and puts forward some methods of estimating text readability and improving text readability.

Unluckily, although scholars have done lots of research on readability and have written a number of papers about it, most research focuses on one or two aspects of readability--either the readability formulas or the application of readability formulas in selecting reading materials or the factors influencing readability and some indices used for measuring readability; little research has been done on how to improve text readability, which is, in fact, another much more complex endeavor, because "the goal of readability research is to match reader and text" (Dreyer, 1984, p.334).

Then what may affect text readability? What can we do to improve text readability?

\section{Factors Affecting Readability}

As has been mentioned above, the readability of a text is affected by a large number of factors. To start with, physical factors such as typeface, font size, spacing, layout, and extra-textual aids like charts, diagrams, pictures, semantic mapping, etc., may influence text readability greatly. Secondly, reader factors such as the readers' prior knowledge about the subject under discussion, their motivation, their interest and their reading ability have considerable influence on text readability because "the act of reading is a process of understanding written language, involving the decoding of written signals and assigning a meaning to them" (Bailin \& Grafstein, 2001, p. 294). In addition, how the writer composes an essay - the vocabulary, the syntactic structure, the organization of the text, and so forth, also affects text readability a lot because "a text may be perfectly grammatical, but certain stylistic properties of some texts may make them relatively more difficult for people to process than others" (Bailin \& Grafstein, 2001, p. 294).

All the factors that may influence text readability are in most cases interdependent. "Each factor may interact with others to produce effects that could not be produced independently" (Bailin \& Grafstein, 2001, p. 298). Having a clear idea of them can undoubtedly help us a lot in producing readable writing. For instance, having a good knowledge of text structure can facilitate comprehensibility and recall; having some idea of text coherence and cohesion can help us know clearly how the configuration of concepts and relations which underlie the surface text are mutually accessible and relevant and how the components of the surface text are interconnected.

Keeping in mind the factors affecting text readability, we can employ as many strategies as possible to produce readable writing, one of which is creating a personal writing style.

\section{Improving Text Readability by Creating a Personal Writing Style}

\subsection{A Brief Introduction to Writing Style}

When it comes to style, different scholars have offered different definitions. For example, Jonathan Swift defines 
style as "proper words in proper places" (qtd. in Irmscher, 1981, p. 162); Gould (1983) argues that style refers to "the way you express yourself in writing, the way words are arranged to carry a message and to create sound and images" (p. 154); David Rosenwasser and Jill Stephen (2008) think of style as "all of a writer's decisions in selecting, arranging, and expressing what he or she has to say" (p. 272).

Despite their using different words in defining style, the scholars admit that style is an overall result determined by the working together of many elements, such as sentence structure, vocabulary, figures of speech, and rhythm. Simply put, style is the way something is written. It emerges from the dialogue a writer has with him-/herself about his/her topic and therefore is personal. That is why we frequently say "the style is the man." For instance, Hemingway was good at writing short, simple, and to-the-point sentences, or good at using "Telegraph language," a term used to define his writing style, and even the longest sentences have a perceived feeling of division that presents "one thing at a time"; Eliot, a pioneer of the modernist revolution, on the contrary, preferred to employ big words and obscure allusions which are hard for the common people to follow.

Admittedly, the styles of some famous writers are unique and inimitable, but we can learn from them and strive to create our own writing style, because writing style, an elusive but essential feature of all texts, if thoughtfully executed, involves the reader and breathes life into a text. By examining the unique use of words, sentence structures and text organization the reader can have a clear idea of our intended meaning and individuality, and can even distinguish correct writing from good writing.

Then how to create our own writing style?

\subsection{Methods of Creating a Personal Writing Style}

\subsubsection{Using Appropriate and Colorful Language}

No matter whom we are writing to and what we are writing about, we should convey our intended meaning by using appropriate and colorful language - words that are suited to the subject under discussion, the audience, and the purpose, and those that are concrete and direct. Using appropriate language or "using the right word at the right time is rather like wearing appropriate clothing for the occasion: it is a courtesy to others, and a favor to yourself--a matter of presenting yourself well in the eyes of the world" (Li \& Diao, 2006, p. 60); using colorful language can help create vivid images in the reader's mind. Specifically speaking, we had better do as follows.

First of all, we must choose the "right" words, because "the 'right' word contributes accuracy and precision to your meaning," while "the "wrong' word, it follows, is inaccurate or imprecise" (Rosenwasser \& Stephen, 2008, p. 274). To choose the "right" words, we should "practice making subtle distinctions among related words" (Rosenwasser \& Stephen, 2008, p. 274). For instance, "misfortune" and "calamity" might mean the same thing to some people, but in fact the two words have a subtle difference. Benjamin Disraeli, an English statesman in the nineteenth-century, once differentiated between the two words by using them in a sentence describing William Gladstone, his political rival: "If Mr. Gladstone fell into the Thames, it would be a misfortune; but if someone dragged him out, it would be a calamity."

Secondly, we need to choose specific or concrete words instead of general or abstract ones, if possible, because specific and concrete words are more informative and expressive and can help make writing clear, exact, vivid, and striking. For example, "telephone," "crystalline," "striped," "flare," "burp," "green belt," and "pop up like corn" all have the pictorial quality and conjure up mental images, something we can physically experience. Such specific and concrete words are as vivid and effective as examples, helping readers see what we mean and have a better understanding of our ideas. For another example, if we want to help the audience "see" Joe's anxiety and nervousness and "hear" the ringing of the phone and conjure up a clear picture of the worried Joe when he received a telephone, the sentence "When the phone finally rang, Joe leaped from the edge of his chair and grabbed for it" can serve the purpose because such words and expressions as "finally," "leaped from the edge of his chair" and "grabbed for it" are quite expressive.

On the contrary, if we use too many general or abstract words in a sentence, the reader may feel confused and even frustrated. For instance, after reading the short paragraph "It was very cold. It was so cold that nobody wanted to stay outside. Everybody found this kind of weather very uncomfortable," the reader cannot imagine how cold and how uncomfortable it was. But if we use some specific and concrete words and provide some details, it will make a great difference, as this example shows:

It was very cold, so cold that the atmosphere itself seemed almost solid. The sidewalks were ridged and lumpy with caked ice, and the dirty crystals of old gray snow crunched underfoot with a dry, splintering sound. The trees were bare black skeletons, their branches like outstretched arms frozen into gestures of dismay. In the playground a deserted sled lay on its back like some great sprawled insect, its runners coated with ice. Even 
children stayed indoors on a day like this. It was too cold to play. (Li \& Diao, 2006, p. 71)

So, although "without the shaping power of abstract diction, concrete evocation can leave us with a list of graphic but ultimately pointless facts," "writing made up only of such words[abstract words] loses contact with experience, with the world that we can apprehend through our senses" (Rosenwasser \& Stephen, 2008, p. 276). To create the best writing, we had better integrate abstract and concrete diction and employ specific and concrete words as long as the situation permits.

Thirdly, we must try to avoid any expression that is so overused, flattened out and colorless that it lacks meaning and not to use any jargon, a highly specialized vocabulary, that cannot be shared by a general audience. Phrases like "better late than never," "busy as a bee," "sick as a dog," and "sink or swim" are so overused that they have lost their originality and effectiveness and therefore, should have no place in writing. Similarly, the insiders' language should not be directed at outsiders, because it may leave most readers bewildered. For instance, if the following sentence, written by a lawyer for other lawyers, is directed at the general audience, it will be unacceptable because few can make sense of it.

The Author hereby indemnifies and agrees to hold the Publisher, its licensees, and any seller of the Work harmless from any liability, damage, cost, and expense, including reasonable attorney's fees and costs of settlement, for or in connection with any claim, action, or proceeding inconsistent with the Author's warranties or representations herein, or based upon or arising out of any contribution of the Author to the Work. (Rosenwasser \& Stephen, 2008, p. 283)

Fourthly, instead of talking around a subject, we must get to the point and attempt to make sentences as concise as possible because "the secret of good writing is to strip every sentence to its cleanest components" (Zinsser, 2001, p. 8). For instance, of the two sentences below, which express the same meaning, Sentence B is obviously much shorter, more direct, and more concise.

A. In the month of May people of different professions from all circles in this city will hold meetings to elect representatives, and these representatives will go to Beijing, the capital, in October to attend a national congress of model workers from the whole country. (Ding, 2011, p. 66)

B. In May people of different professions in this city will elect representatives, who will attend a national congress of model workers in Beijing in October. (Ding, 2011, p. 66)

Finally, we should endeavor never to use the superlative when comparing two things and strive to avoid superlative phrases like "by far the most amazing..." because not only does exaggeration quickly wear out its welcome, but multiple superlatives are also redundant. We should also be careful with terms like "complete(ly)," "absolute(ly)," "perfect(ly)" and "infinite(ly)" because understatement or plain statement is always more effective than overstatement.

In a word, diction can make an enormous difference in the quality of writing, because "If language is incorrect, then what is said is not meant. If what is said is not meant, then what ought to be done remains undone" (Confucius, qtd. in Wyrick, 2008, p. 145). To clearly communicate our ideas to the reader, we must transfer our thoughts onto the paper in proper words.

\subsubsection{Using Active Verbs}

To make our writing vivid and have a unique tone, we had better use active voice instead of passive voice, because a sentence, at its very basic level, is about actors and action, which implies that we need to name the actor first and then describe his/her action. Active voice usually uses fewer words, sounds more vigorous, and is more personal, easier to follow, and easier to remember. For instance, "You are making too much noise" is short and precise, which leaves no doubt about who did what, while "Too much noise was made by him" is insipid, weak and ambiguous, which saps the reader's energy. So it is no exaggeration to say that "The difference between an active verb style and a passive-verb style - in clarity and vigor - is the difference between life and death for a writer" (Anonymous, 2015).

Without doubt, the rule "Using the active voice" does not mean that we should entirely discard the passive voice, which is sometimes absolutely necessary, and "the need of making a particular word the subject of the sentence will often determine which voice is to be used" (Strunk, 1918), but the habitual use of the active voice makes for livelier, more engaging and forcible writing. This is true not only in narration primarily concerned with action, but in other types of writing.

Besides, we had better use verbs instead of their noun forms. Active verbs usually push the sentence forward and enable us to visualize an activity because they require a subject (a noun, a pronoun or a person) to put them in 
motion. For instance, in the sentence "I have made a decision to learn English well," the writer uses the phrase "make a decision" instead of a single verb "decide" and the sentence seems good. Unfortunately, the verb "make" has no very specific meaning of its own and therefore is weak and all-purpose. Since it is not contributing anything to the sense, we can rewrite the sentence as "I have decided to learn English well."

\subsubsection{Providing Sufficient Supporting Information}

It is generally believed that what is obvious to us is obvious to everyone. But one of the main factors that influence the readability of a text is the reader's prior knowledge about the subject, which implies that not everyone has the relevant background knowledge we have had. So, we must provide sufficient supporting information or evidence (facts, illustrations, explanations, etc.) to adequately define, explain, exemplify, or in some other way support our main idea and spare no effort to make the information clear and specific enough for the reader to understand. The two paragraphs below can well illustrate the importance of providing enough supporting information.

A) Living with my ex-roommate was unbearable. First, she thought everything she owned was the best. Second, she possessed numerous filthy habits. Finally, she constantly exhibited immature behavior. (Wyrick, 2008, p. 59)

B) Living with my ex-roommate was unbearable. First, she thought everything she owned, from clothes to cosmetics, was the best. If someone complimented my pants, she'd point out that her designer jeans looked better and would last longer because they were made of better material. If she borrowed my shampoo, she'd let me know that it didn't get her hair as clean and shiny as hers did. My hand cream wasn't as smooth; my suntan lotion wasn't as protective; not even my wire clothes hangers were as good as her padded ones! But despite her pickiness about products, she had numerous filthy habits. Her dirty dishes remained in the sink for days before she felt the need to wash them. Piles of the "best" brand of tissues were regularly discarded from her upper bunk and strewn about the floor. Her desk and closets overflowed with heaps of dirty clothes, books, cosmetics, and whatever else she owned, and she rarely brushed her teeth (when she did brush, she left oozes of toothpaste in the sink). Finally, she constantly acted immaturely by throwing tantrums when things didn't go her way. A poor grade on an exam or paper, for example, meant books, shoes, or any other small object within her reach would hit the wall flying. Living with such a person taught me some valuable lessons about how not to win friends or keep roommates. (Wyrick, 2008, p. 59)

Paragraphs A and B have the same topic sentence: Living with my ex-roommate was unbearable. But in Paragraph B, by adding more supporting evidence - specific examples and details gained through her personal observation, the writer is more likely to convince the reader of her ex-roommate's real character and therefore Paragraph B is much more readable.

\subsubsection{Writing with a Personal Voice}

To create our own writing style, we should write with our own voice.

On the one hand, we must live our life as fully as possible and write something we personally feel strongly and make great efforts to help the reader see things through our eyes, our thoughts, and our attitudes. Only when our writing is original and authentic are we writing with our own voice. Besides, we should be on guard against writing purple or flowery prose or writing something full of esoteric knowledge in the hope of impressing the reader. What we should do is "to strip language clean, to lay it bare down to the bone," as Hemingway once said.

On the other hand, we must have a thorough knowledge of the subject we intend to explore and have a clear idea of how we want to approach it and then write from the heart. Only when our heart is involved in the subject can we get readers involved on that level. Writing from the heart also means holding to a style of expression that is naturally ours, not using any words or phrases that we would never use in spoken language, or in a letter to our best friend because these words and phrases may infect our writing.

Besides, we should be ourselves, never writing like a writer, because "readers want the person who is talking to them to sound genuine" (Zinsser, 2001, p. 20). What we need to do is forget the "craft of writing" we learned at school and just write directly and clearly to let the story tell itself as we used to when we were children.

\section{Conclusion}

From the discussions above we get to know that "how easy a text is for an individual to read is the result of the interaction of a number of different factors" (Bailin \& Grafstein, 2001, p. 292). Just as we take into account the reader's interest, background knowledge and abilities as well as the text's format and difficulty so as to select a book that is suitable for a particular reader, to create our own unique writing style, we need to consider all these factors too. Besides, we must have something to say and employ the "right" words to express ourselves as 
clearly as we can because "the difference between the right word and the almost-right word is as great as that between lightning and the lightning bug" (Mark Twain, qtd. in Li \& Diao, 2006, p. 60). With a personal writing style, we are most likely to produce more readable texts for the general reading public and as a result, elicit a positive response from the reader and achieve our writing purpose.

\section{References}

Anonymous. (2008). What is readability. Retrieved July 10, 2014, from http://www.readability.biz/index.html

Anonymous. (Oct., 2015). The color and power of verbs. Retrieved January 23, 2017, from http://www.wtoutiao.com/p/006kUM.html

Bailin, A., \& Grafstein, A. (July, 2001). The linguistic assumptions underlying readability formulae: A critique. Language \& Communication, 21(3), 285-301. http://dx.doi.org/10.1016/S0271-5309(01)00005-2

Ding, W. D. (2011). A basic course in writing (3rd ed.). Beijing: Higher Education Press.

Dreyer, L. G. (Jan., 1984). Readability and responsibility. Journal of Reading, 27(4), 334-338.

DuBay, W. H. (2004). The principles of readability. Retrieved July 12, 2014, from http://www.docin.com/p-337141884.html

Fry, E. (Nov., 2002). Readability versus leveling. The Reading Teacher, 56(3), 286-291.

Gould, E. (1983). Reading into writing: A rhetoric, reader, and handbook. Boston: Houghton Mifflin Company.

Irmscher, W. F. (1981). The Holt Guide to English: A comprehensive handbook of rhetoric, language and literature. New York: Holt, Rinehart and Winston.

Klare, G. R. (1974-1975). Assessing readability. Reading Research Quarterly, 10(1), 62-102. https://doi.org/10.2307/747086

Li, M., \& Diao, H. Y. (2006). An intermediate course in writing. Beijing: Higher Education Press.

Nystrand, M. (Oct., 1979). Using readability research to investigate writing. Research in the Teaching of English, 13(3), 231-242.

Rosenwasser, D., \& Stephen, J. (2008). Writing analytically (5th ed.). Beijing: Peking University Press.

Strunk, W. Jr. (1918). The elements of style. Retrieved July 14, 2014, from http://www.doc88.com/p-3374781940652.html

Wyrick, J. (2008). Steps to writing well (10th ed.). Beijing: Peking University Press.

Zinsser, W. (2001). On writing well: The classic guide to writing nonfiction (6th ed.). New York: HarperCollins Publishers, Inc.

\section{Copyrights}

Copyright for this article is retained by the author(s), with first publication rights granted to the journal.

This is an open-access article distributed under the terms and conditions of the Creative Commons Attribution license (http://creativecommons.org/licenses/by/4.0/). 